http://jmscr.igmpublication.org/home/ ISSN (e)-2347-176x ISSN (p) 2455-0450

crossref DOI: https://dx.doi.org/10.18535/jmscr/v9i10.20

\title{
Acute Compartment Syndrome in Zaria: A Review of Literature
}

\author{
Author \\ Dr P J Deshi \\ Department of Traumatology and Orthopaedic Surgery \\ Ahmadu Bello University Teaching Hospital, Zari \\ *Corresponding Author \\ Dr P J Deshi \\ Accident and Trauma Care Foundation (ATCF) \\ C/o Zankli Medical Center
}

\begin{abstract}
Over a three year period, 1996-99, Twelve cases of acute compartment syndrome were seen and treated at ABUTH Zaria. There were seven males and five females, age range from five to fifty -five years. The commonest site is the forearm following closed forearm fractures, followed by the leg region. The commonest complicating factor is following closed fracture treatment by the native 'bone setters'. Three of them presented late which despite adequate treatment resulted in gangrene necessitating amputation. Two of them despite fasciotomy had permanent neurological deficit and some mild deformity of the hand. The remaining was seen early enough, treated by adequate fasciotomy and regained full function of the limb.
\end{abstract}

Keywords: Compartment syndrome, acute, traditional bone setters, intra compartmental pressure, capillary perfusion, fasciotomy.

\section{Introduction}

1,3,4,6 Acute compartment syndrome is a condition in which high pressure within a closed fascia (here muscle compartment) reduces capillary blood perfusion below a level necessary for tissue viability. Compartment syndrome develops in skeletal muscles enclosed by relatively noncompliant Osseo-fascial boundaries. A buildup of pressure within the muscle compartment is not easily dissipated, owing to the inelasticity of the muscle investing fascia. If pressure remains sufficiently high, for several hours, normal function of the muscle and nerve is jeopardized and myoneural necrosis eventually will result. Permanent loss of function and limb contractive may occur. A prompt diagnosis and
Decompression of the compartment is therefore essential in order to reinstate capillary perfusion and prevent irreversible sequel. Usually decompression is accomplished by fasciotomy, which allows the muscle to swell out of their tight fascial envelope. Compartment syndrome could occur in the legs, thigh, buttock, foot, arm, forearm, hand and even fingers.

\section{Patients \& Methods}

All cases of acute compartment syndrome treated between September 1996 and September 1999 were included in the study. The manual retrieval method was used to retrieve the clinical records of the patient from the medical record department. The records were easy to trace since the author 
was personally involved in the management of most of these patients.

All the patients under review were admitted through the casualty at ABUTH Zaria where the initial clinical assessment, resuscitation, diagnosis and investigations were done.

Once the diagnosis of compartment syndrome was made, emergency fasciotomy was carried out in the casualty, usually under light general anesthesia. The immediate outcome of fasciotomy was noted in each case and subsequently all patients were followed up in the outpatient clinic after discharge to assess functional outcome and any resultant complications.

Diagnosis was based essentially on clinical history and clinical examination alone which were found to be sufficient. The clinical judgment relied on the syndrome of the so called 5Ps: pain, palor, pulseness, parasthesia and paralysis in varying combinations. Intracompartmental pressure were not measured nor any nerve conduction studies carried out.

\section{Results}

Twelve cases of acute compartment syndrome were treated over a three year Period. There were nine males, three females, the youngest patient was two years and the oldest was fifty five years.

The commonest site in this study is the forearm, followed by the leg region. There was a case of compartment syndrome of the Middle finger following trauma while playing basketball as well as one case of the thigh and a case of the hand. Most of the patients had visited the native bone setters where the affected limbs were splinted at presentation in casualty. Road traffic accident accounted for most of the cases, followed by fall from heights, with sports injury accounting for one and post-surgery (after plating of the Tibia) accounting for one. Seven of the patients had fully functional recovery, two had residual neurological deficit and mild deformity of the hand (a mild form of Volkmann's Ischemia contracture). Three patients presented rather too late and the limbs were amputated due to irreversible damage despite the fasciotomy. All patients irrespective of their state of presentation had fasciotomy and in the forearm and leg, all the various compartments of the respective limbs were effectively decomposed. (See table)

\section{Discussion}

1,2,8,9,10,11 Acute compartment syndrome of the limbs is a surgical emergency and should be treated as such. Other areas in surgery where there could be compartment syndrome requiring urgent surgical intervention include raised intracranial pressure, tension pneumothorax, raised intraocular pressure, heamopericardium (cardiac tamponate) and priapism. A wide variety of injuries may initiate compartment syndrome of the limbs. In our study, most cases are due to fractures especially of the forearm complicated by traditional bone setting. It may also occur in association with contusions, bleeding disorder, burns, trauma, post ischemia swelling after arterial injury or thrombosis, exercise, drug or alcohol overdose or venous obstruction.

4,6 A modified Matsen classifications divides the aetiological factor into Problems that decrease the size of the compartment and factors that increase the fluid content in the compartment. In the second group, the fluid that accumulates may be primary oedema, hemorrhage or a combination of oedema and hemorrhage.

Decrease in the compartment size occurs in the following:

i) Constructive dressing and plaster casts. The cast lowers tissue compliance and also lowers the threshold of fluid accumulation.

ii) Closure of fascial defects. Inadvertent closure of fascial defects in muscles may decrease the total compartment volume.

iii) Thermal injuries- As seen in circumferential third degree burns by the inelastic constricting eschar decreasing the volume of the underlying compartments and thermal injury being associated with massive formation of oedema fluid. 
$5,6,7$ Increase in compartmental content include conditions such as post ischemic swelling e.g. post operatively after the use of tourniquets, prolonged immobilization with limb compression as seen in drunks and drug overdose patients. Exertion, extreme form of it or exercise may initiate an acute or chronic compartment syndromes of which abate on the stoppage of the exercise. Other causes include venomous snake bites, accumulation of hemorrhage, as seen in haemophiliacs, massive tissue injury and in fractures and osteotomies.

Diagnosis of acute compartment syndrome is usually clinical, requiring a high index of suspicion, relying on the five cardinal signs and symptoms of the so called 5Ps

i. Pain -usually a deep throbbing feeling of unrelenting pressure, greater than is expected from the primary problem.

ii. Palor- with decreasing tissue perfusion, digital palor becomes obvious

iii. Paraesthesia- Abnormal sensation as a result of increased pressure on the nerves

iv. Paralysis- May be due to direct nerve or muscle ischernia or a combination of both

v. Pulselessness- the arterial pulse may be absent while poor capacity filling may result.

Table 1- Anatomical site of compartment syndrome

\begin{tabular}{|l|l|}
\hline Forearm & 6 \\
\hline Leg & 3 \\
\hline Thigh & 1 \\
\hline Finger & 1 \\
\hline Hand & 1 \\
\hline
\end{tabular}

Table II Aetiological Factors Causing Compartment Syndrome

\begin{tabular}{|l|l|}
\hline Road traffic accidents & 6 \\
\hline Fall from height & 4 \\
\hline Sports Injury & 1 \\
\hline Post operation (Tibial Plating) & 1 \\
\hline
\end{tabular}

Table III -Presentation in Hospital

\begin{tabular}{|l|l|}
\hline First visited Native bone setters & 9 \\
\hline First Presentation in Hospital & 3 \\
\hline
\end{tabular}

Table IV Outcome of Surgery (Fasciotomy)

\begin{tabular}{|l|c|}
\hline Full functional recovery & 7 \\
\hline $\begin{array}{l}\text { Residual Neurological deficit and } \\
\text { Volkmann's Ischaemic contracture }\end{array}$ & 2 \\
\hline $\begin{array}{l}\text { Compartment Syndrome } \\
\text { Complicated by gangrene }\end{array}$ & 3 \\
\hline
\end{tabular}

Table V Age Distribution

\begin{tabular}{|l|l|}
\hline $1-10$ years & 4 \\
\hline $11-20$ years & 2 \\
\hline $21-30$ years & 2 \\
\hline $31-40$ years & 2 \\
\hline $41-50$ years & 1 \\
\hline $51-60$ years & 1 \\
\hline
\end{tabular}

Differential diagnosis - of acute compartment syndrome include nerve injuries and arterial injuries.

\section{Laboratory Test}

Intra-compartment pressure - often one does not need to measure the intra- compartment pressure before making a diagnosis and instituting treatment. But in Centre's where there are facilities, it is worthwhile to measure the intracompartmental pressure. There is the needle technique as popularized by René man and white side and the infusion techniques advocated by master et al. Although there is controversy as to what level of intra-conpartment pressure that warrants a fasciotormy it is recommended that intra-compartmental pressure greater than $30 \mathrm{mmHg}$ combined with other positive clinical findings necessitate a fasciotomy. Fasciotomy is a relatively straightforward procedure, ensuring that the whole fascia is incised until the underlying muscle bulk bulges out and usually, the whole length of the compartmental fascia in incised. In the forarm, all the three compartments are decomposed while two incisions could be enough to decompresses all four compartments of the leg. Occasionally, prophylactic faciotomy is carried out with a high probability of developing Compartment syndrome especially in such surgical procedures as tibia osteotomies or leg lengthening procedures or when the tibia is used as a donor bone graft. 
In Conclusion, acute Compartment Syndrome is a fairly common complication of limb injuries even though patients in our environment usually present late when complications have set in or do not even report at all. Its assessment and treatment is usually a surgical emergency of fasciotomy delay of which may have grievous consequences for the limb.

\section{References}

1. Kelly G.C. and EISEMAN .B. Civilian Vascular Injuries J. Trauma 15: 507 - 514 1975.

2. Hill, R.L and Brokes, B: Volkmann's ischemic Contracture in Haemophiliac. Am. Surg, 103: 444 445, 1963.

3. Patman, R.D: Compartment Syndromes in peripheral vascular surgery. Clin. Orthp 113: 103110, 1975.

4. Reneman, R.S. the anterior and Lateral Compartment Syndrome of the leg. The Hague, Mouton, 1968.

5. Wofort, F>G, Mogelvang, L>/. C and filtzer, H.S Anterior tibias Compartment syndrome following muscle hernia repair. Arch surg, 106: 97 - 193.

6. Ellis, A disabilities after tibial shaft fractures, with special reference to Volkmans Ischaemic Contracture. J. Bonne Jont surg, 40b: 190 - 197, 1958.

7. Jacob, J.E compartment syndromes. Int. Surg, 59: 542 - 543, 1974

8. Jackson, J.P and Waugh, W. The technique and Complications of Upper tibial osteotomy. A review of 226 operations. J. Bone Joint surg., 566B: 236 $-234,1974$.

9. Mubarak, S.J and Carsu IN. C: Volkmann's contracture in Children: aetiology and Prevention. J. Bone Jont surg., 61B:285 - 293, 1979.
10. Mubarak S.J and Owen, C.A Compartment Syndrome and its relation to the crush. Syndrome. A spectrum of disease. Clin orthop. 13:81 - 89, 1975.

11. Thomas J.J Nerve Involvement in the Iszhaemic Paralysic and contracture of Volkmann. Ann surg. / 49: 330, 1909. 